\title{
AVALIAÇÃO DO EFEITO DA FRAÇÃO VOLUMÉTRICA DA FASE DISPERSA EM UM ESCOAMENTO MULTIFÁSICO ÁGUA-ÓLEO NÃO ISOTÉRMICO EM JUNÇÃO TIPO T.
}

\author{
D. P. B. ARAÚJO ${ }^{1}$, S. R.F. NETO ${ }^{2}$ \\ ${ }^{1}$ e 2 Universidade Federal de Campina Grande, Centro de Ciência e Tecnologia \\ Unidade Acadêmica de Engenharia Química \\ Laboratório de Pesquisa em Fluidodinâmica e Imagem - LPFI \\ E-mail para contato: danilo_barros_pablo@hotmail.com
}

\begin{abstract}
RESUMO - O presente Trabalho tem como objetivo avaliar o efeito que a variação da fração volumétrica da fase dispersa em um escoamento bifásico água-óleo não isotérmico exercem sobre o padrão de escoamento em junção do tipo T. Adotou-se a abordagem Euleriana-Euleriana e o modelo matemático formado com as equações de conservação de massa, momento linear e de energia, como também as equações de turbulência (k-ع padrão e SST) e equações constitutivas. O modelo foi definido com o auxílio do pacote comercial Ansys CFX para obtenção dos resultados das simulações numéricas. Os resultados foram confrontados com dados experimentais e após o tratamento estatístico, verificou-se, uma ótima concordância entre os resultados numéricos e experimentais.
\end{abstract}

\section{INTRODUÇÃO}

Escoamentos multifásicos estão presentes em diversos processos naturais (chuvas, neblinas) e industrias (caldeiras, condensadores, produção de petróleo), dessa forma estudar os fenômenos de transporte envolvidos nesse tipo de escoamento tem uma vasta aplicabilidade. Segundo Brantland (2010) um dos aspectos mais desafiantes em lidar com escoamentos multifásicos é a grande variedade de padrões de escoamento que podem ser obtidos, e esses padrões variam com a fração volumétrica, velocidade, temperatura, etc.

Em aplicações industriais, muitas vezas, tem-se a preferência por determinado padrão de acordo com a aplicabilidade do escoamento. Por exemplo, no transporte de petróleo e seus derivados é preferível um escoamento do tipo anular para diminuir o atrito com a tubulação e assim ter um gasto menor na energia de bombeamento. Neste padrão, utiliza-se a água para a formação do anel junto a tubulação que envolve o fluxo de petróleo. Já o padrão estratificado é uma forma muito conveniente de evitar a formação de emulsões de água em oleodutos (KRUSCHE, 2017).

Araújo, M.V. (2014) estudou o escoamento bifásico de água e óleo em junções T na presença de vazamento, tendo como objetivo estudar a termofluidodinâmica desse tipo de escoamento. Para isso foi construído um domínio tridimensional e foi simulado o escoamento

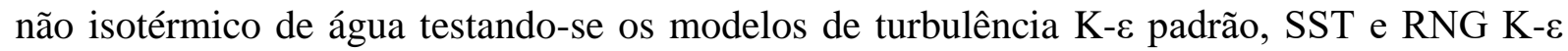




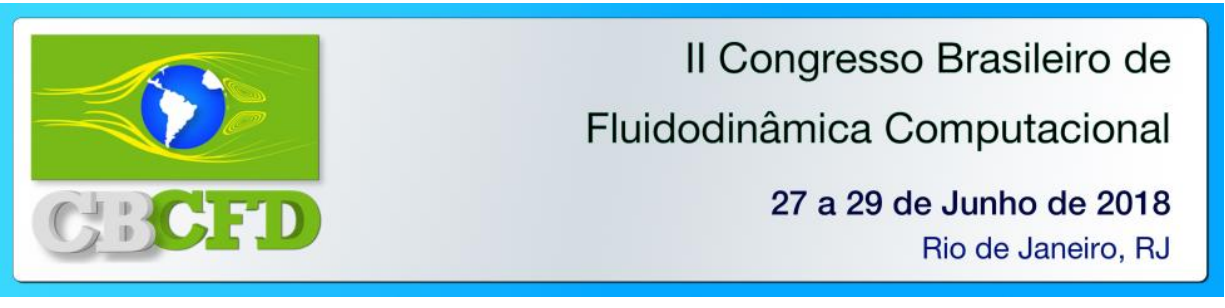

utilizando as equações da conservação de massa, momento e energia. Foram simulados os escoamentos bifásicos de água-óleo em uma junção $\mathrm{T}$ com vazamento, variando-se a fração volumétrica de óleo e as temperaturas das misturas nas seções de entrada. Comparando os perfis de velocidade e temperatura com dados experimentais observou-se que o modelo K- $\varepsilon$ padrão representou satisfatoriamente o comportamento do escamento. Notou-se que quanto menor a fração volumétrica de óleo no escoamento, maior a pressão a montante do vazamento e que a região de encontro entre o duto principal e o duto secundário apresentou os maiores gradientes de pressão.

\section{METODOLOGIA}

O Domínio físico estudado é baseado no trabalho de Naik-Nimbalkar et al. (2010), onde o domínio computacional com as respectivas dimensões é ilustrado conforme mostra a Figura 1a. Já a malha numérica que a assim como a geometria foram geradas no Software Salome, que é um software de código aberto, é formada por 200256 elementos tetraédricos conforme pode ser observado na Figura 1b.

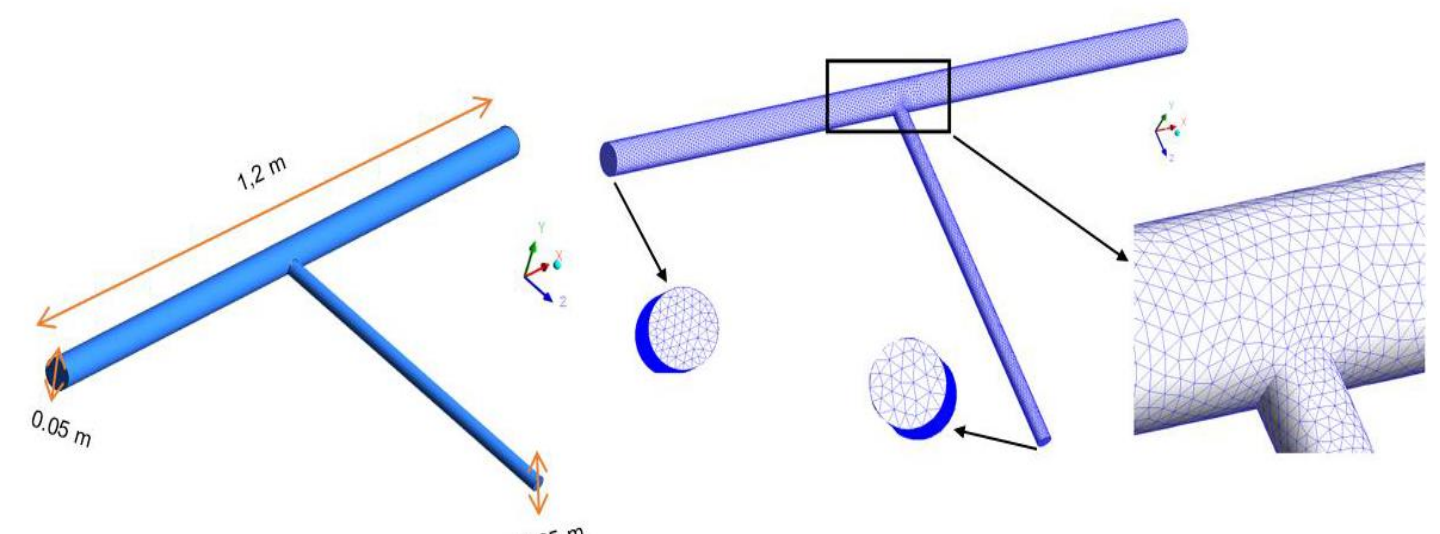

(a)

(b)

Figura 1 - (a) Dimensões do domínio de estudo computacional e (b) Malha numérica criada para o domínio computacional.

Para as simulações numéricas foi utilizado o ANSYS CFX ${ }^{\circledR}$ 15.0, adotando-se a abordagem Euleriana-Euleriana e os modelos mateméticos formados com as equações de massa, momento linear e de energia, as equações de turbulência (K-E padrão e SST) e equações constitutivas.

As condições de contorno utilizadas foram velocidade de entrada $1 \mathrm{~m} / \mathrm{s}$ no duto de raio maior e temperatura de $303 \mathrm{~K}$, já no duto de raio menor a velocidade de entrada foi $0.5 \mathrm{~m} / \mathrm{s} \mathrm{com}$ uma temperatura de $318 \mathrm{~K}$ e um fração volumétrica da fase dispersa óleo variando de $0.1 \%$ a 7\%. Já na saída foi especificada uma pressão de 101325 Pa. 


\section{RESULTADOS}

$\mathrm{Na}$ figura 2a é representado o perfil de temperatura adimensional, sendo os resultados numéricos comprados com os dados experimentais obtidos por Naik-Nimbalkar et al. (2010). Já na figura $2 b$ tem-se o perfil de velocidade adimensional obtido utilizando o modelo de turbulência K- $\varepsilon$ e o SST, sendo também realizado uma comparação com os dados experimentais de Naik-Nimbalkar et al. (2010).
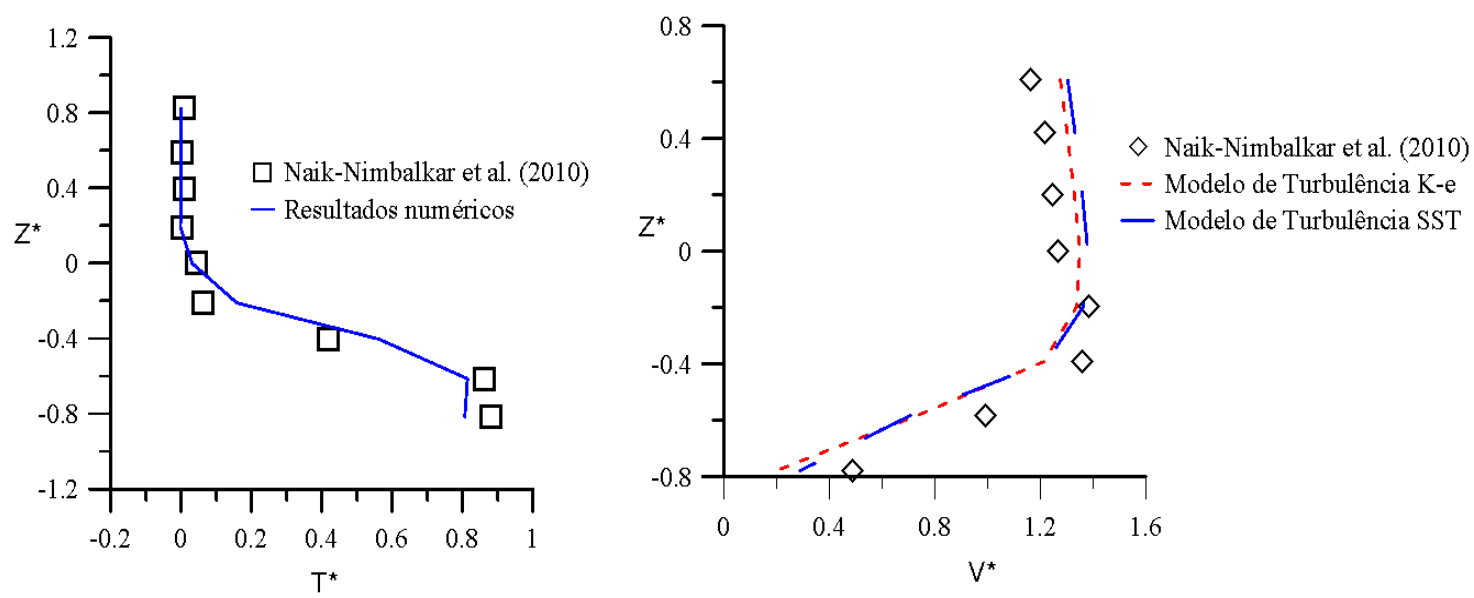

Figura 2 - (a) Perfil de Temperatura adimensional e (b) Perfil de velocidade adimensional.

Ao observar os perfis de temperatura e velocidade adimensionais é possível identificar uma boa concordância com os dados experimentais, onde calculando-se o desvio padrão obteve-se um valor de $1.70 \%$ para o perfil de temperatura e $5 \%$ para o perfil de velocidade. Atestando dessa forma a boa qualidade dos resultados numéricos obtidos pela malha numérica criada no presente trabalho.

Ainda pode-se observar através da figura $1 \mathrm{~b}$ que o modelo de turbulência $\mathrm{K}-\varepsilon$ padrão muito embora não tenha um tratamento dos resultados tão bom quanto o modelo SST na camada limite, onde existem os maiores gradientes de pressão, temperatura e velocidade, ajustou-se muito bem aos dados experimentais.

Nas figuras 3a e 3b é possível avaliar o efeito da fração volumétrica da fase dispersa (óleo) sobre o perfil e o campo de velocidade superficial da fase continua (água), respectivamente. Sendo possível observar que até $5 \%$ de óleo na corrente fluida a velocidade superficial da água não é alterada de maneira significativa, porém para uma fração volumétrica de $7 \%$ começa a observar um aumento do perfil de velocidade, e isso deve-se ao fato na mudança da dinâmica do escoamento devido a maior interação entre as fases contínuas e dispersa. 

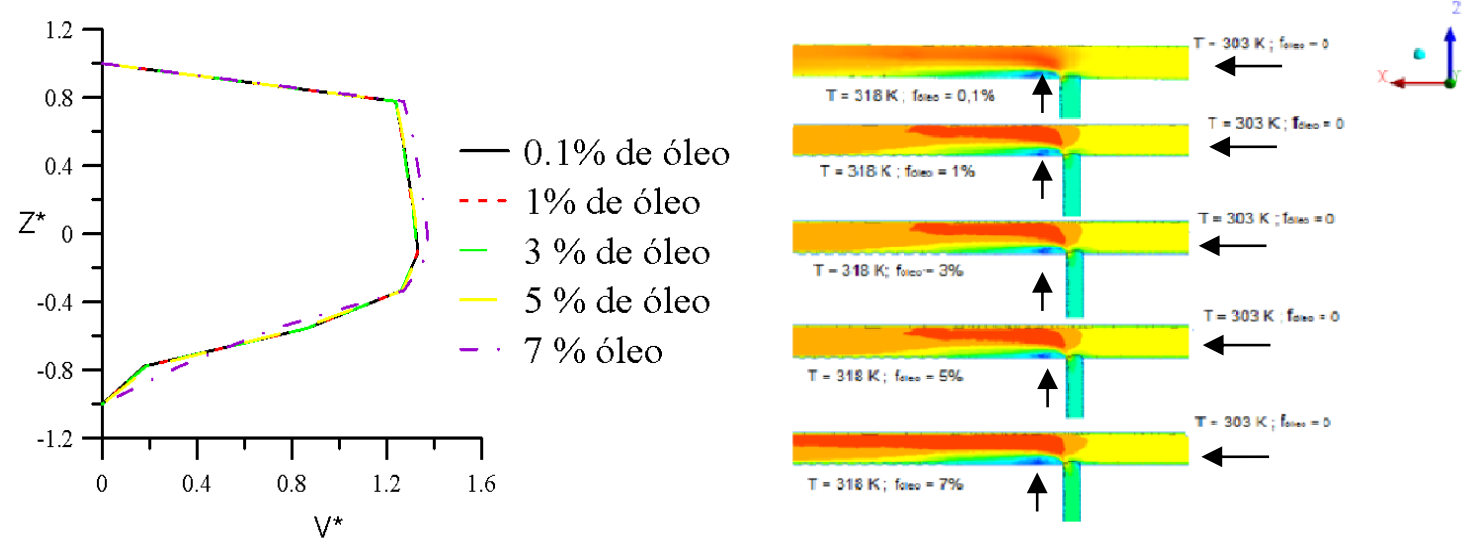

Figura 3 - (a) Perfil de velocidade adimensional para diferentes frações volumétricas da fase dispersa óleo e (b) Campo de velocidade superficial da fase contínua água.

No campo de velocidade superficial da fase contínua ilustrado na figura $3 b$, observa-se a existência de zonas de baixa velocidade na região logo após a conexão da junção T, sendo essas zonas atribuídas a zonas de recirculação.

\section{CONCLUSÃO}

Os resultados da simulação bifásica água-óleo em um misturador tubular tipo T foram comparados e analisados com dados experimentais, atestando assim que os modelos matemáticos utilizados são capazes de predizer todos os fenômenos físicos estudados. Foi possível avaliar ainda que para frações volumétricas de óleo fase (dispersa) maiores que 5\% influenciou de maneira significativa as componentes de velocidade superficial da fase contínua (água).

\section{REFERÊNCIAS}

ARAÚJO, Morgana de Vasconcellos. Estudo Numérico do Escoamento Bifásico de Água e Óleo em Conexões Tê na Presença de Vazamento. 2014. 87 f. Dissertação (Mestrado em Engenharia Química), Universidade Federal de Campina Grande, 2014.

BRATLAND, Ove. Pipe flow 2: multi-phase flow assurance. 2010. Apostila

KRUSCHE, D. B. Análise não linear de instabilidades em escoamento bifásico líquido-líquido no padrão estratificado. 201790 f. Dissertação (Mestrado em Engenharia Mecânica) Faculdade de Engenharia Mecânica, Universidade Estadual de Campinas, Campinas, 2017.

NAIK-NIMBALKAR, V. S.; PATWARDHAN, A.;BANERJEE, I.; PADMAKUMAR, G. e VAIDYANATHAN, G. Thermal mixing inT-junctions. Chemical Engineering Science, v. 65, n. 22, p. 5901-5911, 2010. 